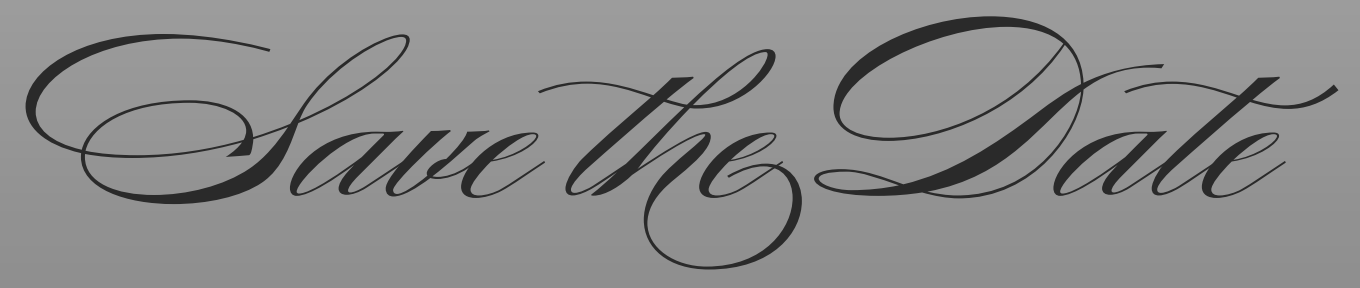

IPA/SEPG Joint

International Congress

彭 SEPTEMBER 2019 獪

Santiago de Compostela, Spain

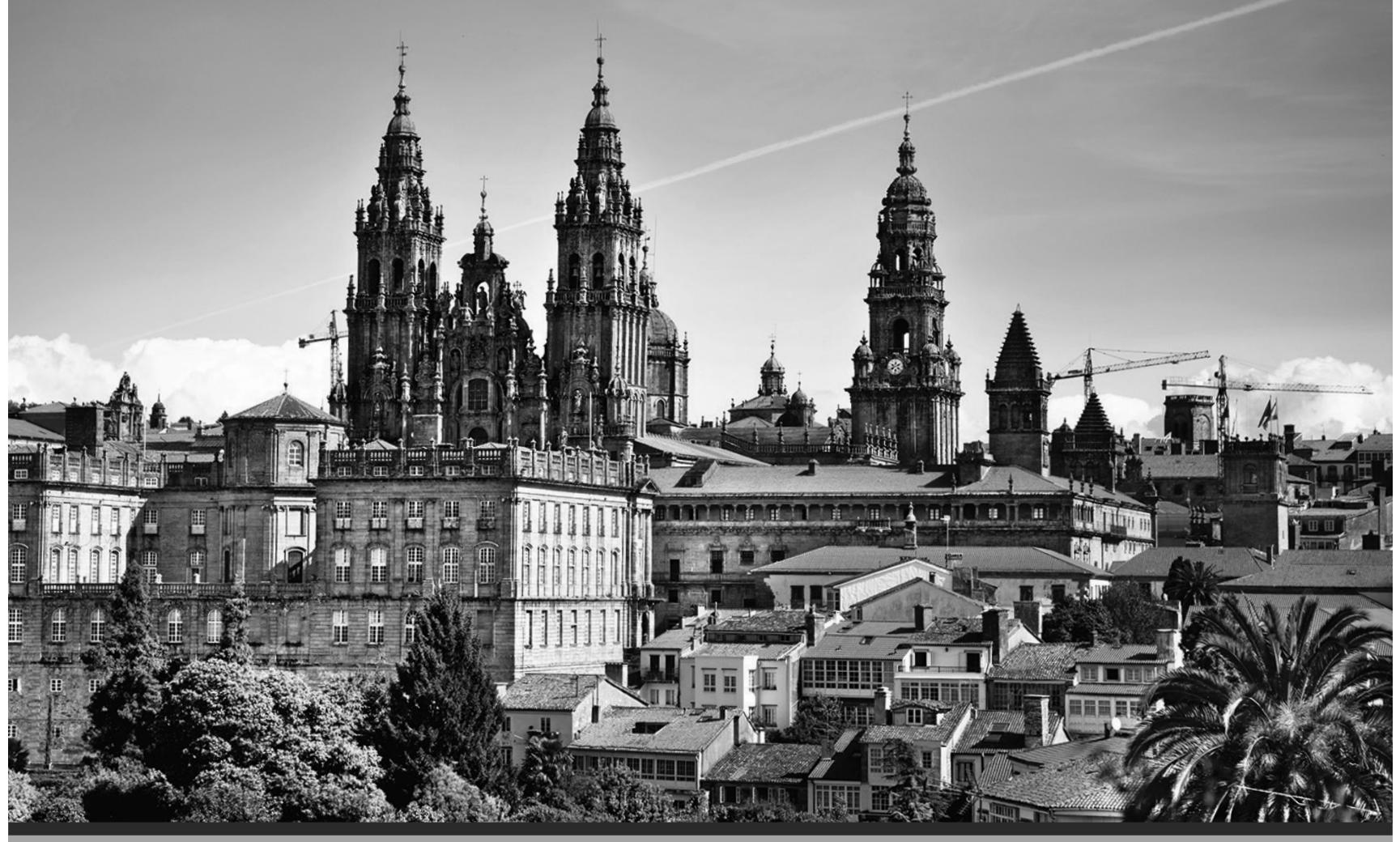

International Psychogeriatric Association
Better Mental Health for Older People www.ipa-online.org/2019congress 


\section{International Psychogeriatric Association}

EIALA

Better Mental Health for Older People

The IPA Complete Guides to

Behavioral and Psychological Symptoms of Dementia (BPSD)

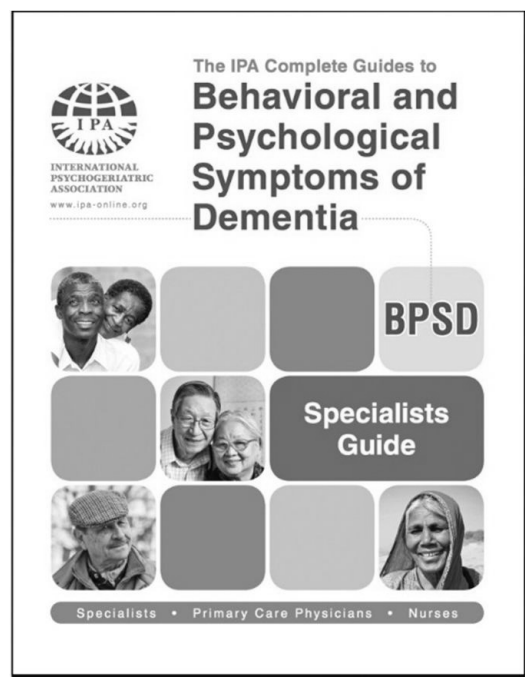

Specialists Guide Recently Revised!

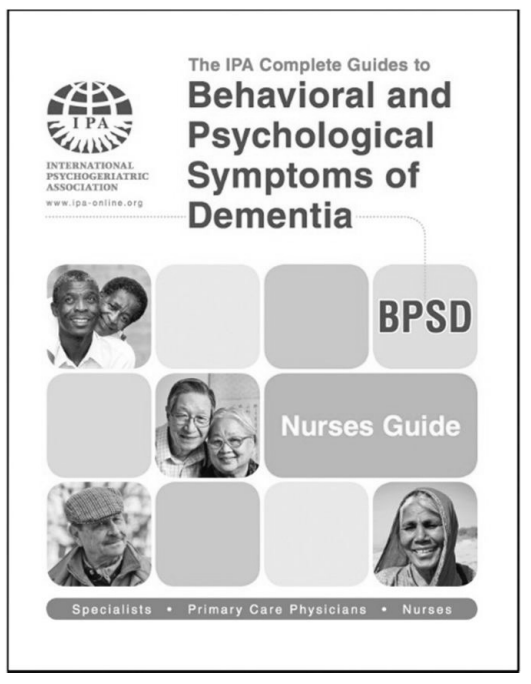

Nurses Guide

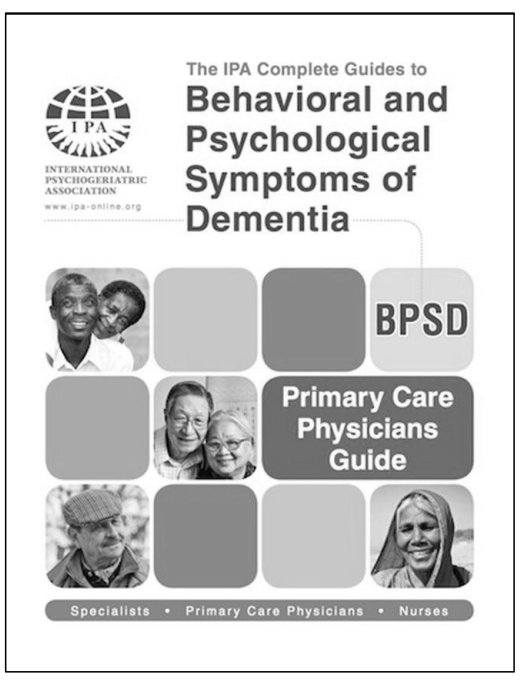

\section{Primary Care Physicians Guide}

The Only Resources You Need for All of the Members of Your Team!

The IPA Complete Guides to Behavioral and Psychological Symptoms of Dementia (BPSD) are available to all members of the International Psychogeriatric Association (IPA).

To learn more about IPA and access the Guides, please visit: www.ipa-online.org 


\section{International Psychogeriatric Association I PA $=$ Better Mental Health for Older People}

\section{Submit an Article for the IPA Bulletin!}

The IPA Bulletin is the quarterly newsletter of the International Psychogeriatric Association (IPA). In addition to news about IPA and related organizations, the IPA Bulletin contains articles on recent advances and initiatives in the field in of psychogeriatrics. The IPA Bulletin reaches all the members of IPA, including our affiliates around the world.

Research and Practice. The Research and Practice section of the IPA Bulletin highlights recent advances in psychogeriatrics and related fields. Articles from all fields related to the mental health of older people are welcome.

Around the World. The Around the World section of the IPA Bulletin features articles by clinicians and researchers which report on activities and issues within their country or region. These articles seek to educate others on the state of the field in other countries and provide unique perspectives from around the world.

To learn more about the IPA Bulletin, visit our website:

www.ipa-online.org 


\section{CAMBRIDGE}

\section{Medicine}

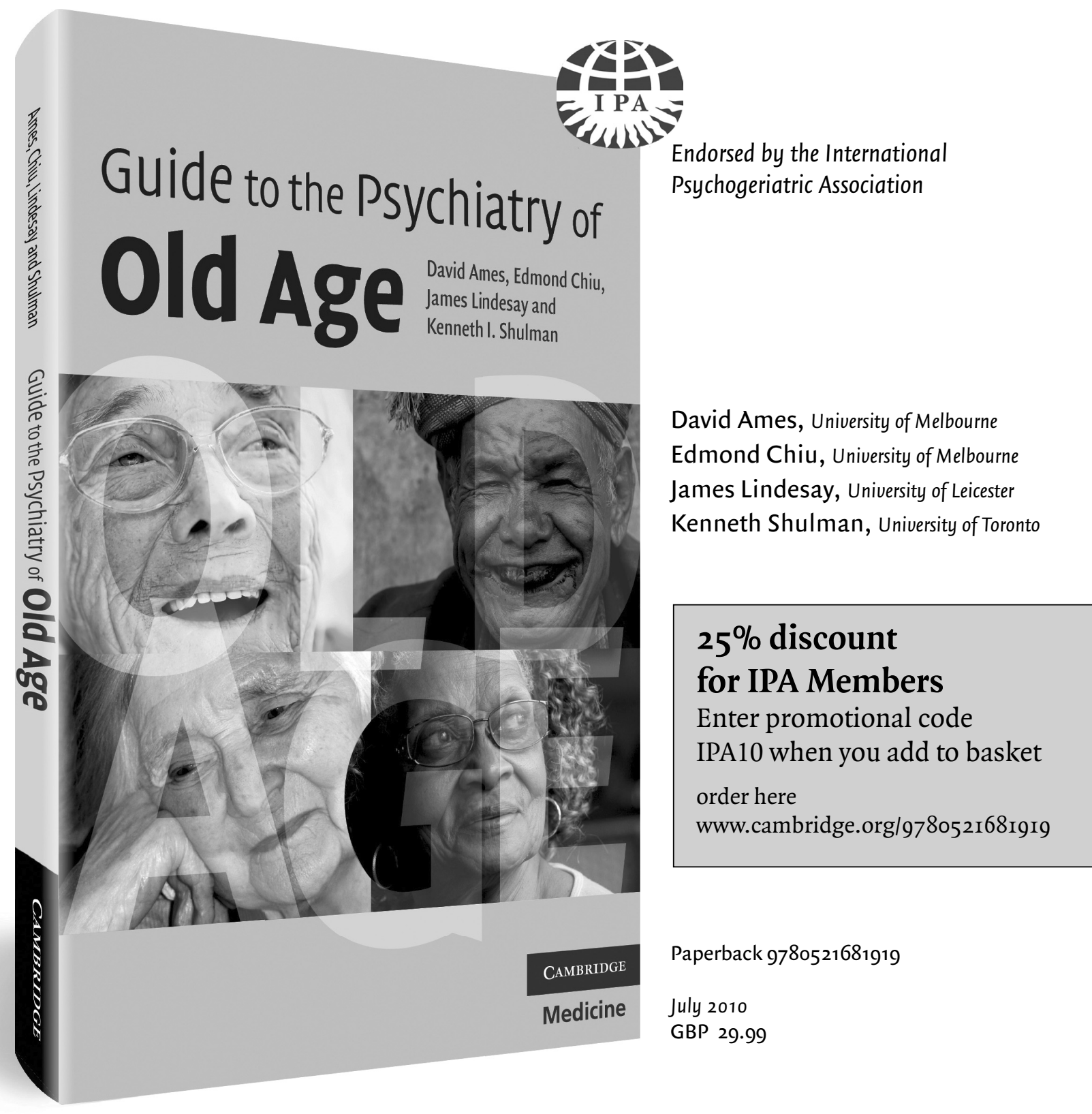

\section{Compact, accessible and affordable}

Each chapter is sharp, clear and practical, enhanced by tables and diagrams for quick assimilation and reference on the ward or in the clinic Coverage also includes legal and ethical issues, and the neglected topic of alcohol and drug abuse in the elderly 


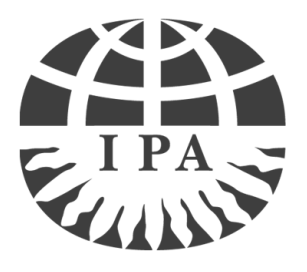

\section{About IPA}

\section{International Psychogeriatric Association}

Better Mental Health for Older People

IPA NEEDS YOU!

The International Psychogeriatric Association (IPA), founded in 1982 and representing members in more than 50 countries, is a unique and diverse professional healthcare community promoting better geriatric mental health - across disciplines, across borders, and across geriatric issues. Psychiatrists, scientists, neurologists, geriatricians, primary care physicians, epidemiologists, nurses, psychologists, occupational therapists, social workers, and many other healthcare professionals come to the IPA community from all around the world to discuss, learn, share and research information about behavioral and biological aspects of geriatric mental health. IPA promotes research and education, facilitates an international exchange of ideas, and fosters cross-cultural understanding of the latest developments in the field.

\section{IPA Membership}

The International Psychogeriatric Association (IPA) encourages professionals from all backgrounds related to geriatric mental health to join our healthcare community. Here are some of the many benefits of joining IPA:

- Unique opportunities to interact with colleagues around the world how share an interest in advancing research, education, and theory about mental health care in older adults.

- Valuable discounts on participation in education and scientific meetings which reflect the full spectrum of disciplines related to psychogeriatrics. Reduced registration rates for the annual IPA International Congress and IPA Regional Meetings are included.

- Relevant publication on updates in the field, including International Psychogeriatrics, IPA's peer reviewed journal which publishes twelve issues per year and additional special-focus supplements.

- Access to online educational materials and The IPA Complete Guides to Behavioral and Psychological Symptoms of Dementia (BPSD).

- Subscription to the IPA Bulletin, IPA's newsletter which features articles on advances in the field and information on upcoming programs around the world.

- Participation in the IPA Member Forums - smaller member groups which enable members to connect with one another and collaborate on research and clinical care practices. These forums reflect the diversity of interests within geriatric mental health.

\section{How to Join}

To learn more about IPA and become a member, please visit our website: www.ipa-online.org. IPA offers a one-year membership for $\$ 160$ USD. One-year student or retired memberships are available for $\$ 99$ USD. A limited number of Lifetime Memberships are also available for $\$ 1000$ USD. The IPA Secretariat is available to answer any questions you may have about IPA or membership. Please contact us at +14149189889 or by email at info@ipa-online.org.

Have Questions? Contact us! International Psychogeriatric Association 555 East Wells Street, Suite 1100

Milwaukee, WI 53202

United States

Phone: +1 4149189889

Fax: +1 4142763349

Twitter: @IPA_Online

www.ipa-online.org

info@ipa-online.org

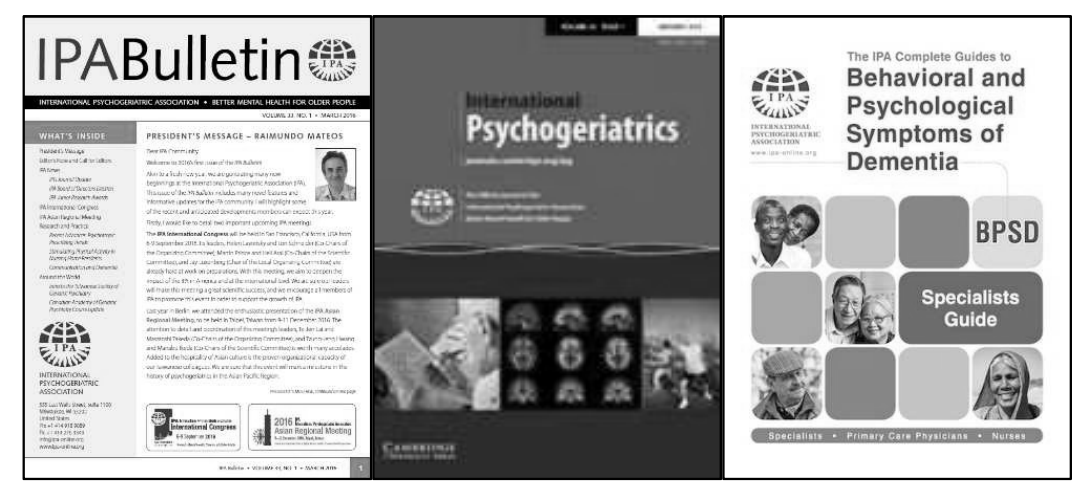




\section{International psychogeniatrics

\section{Scope and contributions}

International Psychogeriatrics is written by and for those doing clinical, teaching, and research work with older people. It is the official journal of the International Psychogeriatric Association (IPA) and is published by Cambridge University Press, Cambridge, UK. Although it is primarily concerned with psychogeriatrics, the journal welcomes contributions from all concerned with the field of mental health and aging. Original research papers are particularly sought.

Contributions include original research articles, reviews of the literature, book reviews, letters to the editor, and editorials. Apart from editorials and book reviews, which are commissioned, contributions to International Psychogeriatrics are spontaneously written and submitted by authors. Papers are usually reviewed by two expert reviewers selected by the Editor-in-Chief. At present, about one-third of the papers submitted are accepted for publication. The journal's Science Citation Index impact factor is 2.423 (2016). Submission of a paper implies that it is neither under consideration for publication elsewhere, nor previously published in English. Manuscripts must be formatted double-spaced with ample margins on all sides and the pages should be numbered. International Psychogeriatrics uses the spelling of American English. Manuscripts written by those whose primary language is not English should be edited carefully for language prior to submission. The journal has a Language Assistance Panel consisting of both native English speakers willing to check mauscripts for style prior to submission, and bilingual experts willing to assist with the translation of manuscripts into English. Further details including contact information for individual panel members can be found at both the journal and IPA websites (journals.cambridge.org/ipg and www.ipa-online.org).

An up to date version of the journal's instructions for contributors can be found at the International Psychogeriatrics website journals. cambridge.org/ipg. Please read these instructions carefully before submitting articles. Articles that are not prepared in accordance with these guidelines will be returned to authors.

Manuscripts should be submitted online via our manuscript submission and tracking site, <http://mc.manuscriptcentral.com/ipg>. Full instructions for electronic submission are available directly from this site.

\section{Important Addresses}

Office of the Editor-in-Chief

DilipV. Jeste, Editor-in-Chief

International Psychogeriatrics

Sam and Rose Stein Institute for Research on Aging

University of California, San Diego

9500 Gilman Drive \#0664

San Diego. CA 92093, USA

Email:ipaj-ed@cambridge.org

\section{For business matters:}

\section{Kate Filipiak}

Managing Editor, International Psychogeriatrics

International Psychogeriatric Association

555 E. Wells Street,

Suite 1100

Milwaukee,WI 53202

United States

Email:ipa@ipa-online.org

Tel: +14149189889

Fax: +14142763349

Web: www.ipa-online.org

\section{For book review matters:}

\author{
Barton W. Palmer \\ University of California, San Diego \\ 8950 Villa La Jolla Drive, Suite B122 \\ La Jolla, CA 92037, USA
}

Email:

bpalmer@ucsd.edu

This journal issue has been printed on FSC-certified paper and cover board. FSC is an independent, non-governmental, not-for-profit organization established to promote the responsible management of the world's forests. Please see www.fsc.org for information.

Enquiries about advertising should be sent to the Journal's Promotion Department of the Cambridge or American Branch of Cambridge University Press. 


\title{
International Psychogeriatrics
}

\author{
Issue Theme: Quality of Care for Frail Older Adults
}

\section{CONTENTS}

Guest Editorial 1255 Quality of care for frail older adults Kirsten Moore

Theme Articles 1259 Quality of care for frail older persons in a homecare setting: what is it and how can it be measured? Jiska Cohen-Mansfield, Adi Hannah Sela, Esther lecovich and Hava Golander

1269 "I Can't Do This Alone": a study on foreign domestic workers providing long-term care for frail seniors at home Wai Jia Tam, Gerald Choon-Huat Koh, Helena Legido-Quigley, Ngoc Huong Lien Ha and Philip Lin Kiat Yap

1279 Person-centered care in Norwegian nursing homes and its relation to organizational factors and staff characteristics: a cross-sectional survey Irene Røen, Øyvind Kirkevold, Ingelin Testad, Geir Selbæk, Knut Engedal and Sverre Bergh

1291 A randomized controlled trial examining the impact of aged care residents' written life-stories on aged care staff knowledge and attitudes Michelle Dennerstein, Sunil S. Bhar and Jencie J. Castles

Original Research 1301 The relationship between gait dynamics and future cognitive decline: a prospective pilot study in geriatric patients Articles Lisette H. J. Kikkert, Nicolas Vuillerme, Jos P. van Campen, Bregje A. Appels, Tibor Hortobágyi and Claudine J. C. Lamoth

1311 Older marijuana users' marijuana risk perceptions: associations with marijuana use patterns and marijuana and other substance use disorders Namkee G. Choi, Diana M. DiNitto and C. Nathan Marti

1323 Validation of the Older Adult Social Evaluative Scale (OASES) as a measure of social anxiety Brian C. Kok, Vanessa K. Ma and Christine E. Gould

1333 A longitudinal study of cognitive decline in rural Tanzania: rates and potentially modifiable risk factors Jessica Heward, Lydia Stone, Stella-Maria Paddick, Sarah Mkenda, William K. Gray, Catherine L. Dotchin, John Kissima, Cecilia Collingwood, Bernadetha Swai and Richard W. Walker

1345 Effect of SSRI and calcium channel blockers on depression symptoms and cognitive function in elderly persons treated for hypertension: three city cohort study Phillip J. Tully, Ruth Peters, Karine Pérès, Kaarin J. Anstey and Christophe Tzourio

1355 Global cerebrovascular burden and long-term clinical outcomes in Asian elderly across the spectrum of cognitive impairment Xin Xu, Yiong Huak Chan, Qun Lin Chan, Bibek Gyanwali, Saima Hilal, Boon Yeow Tan, Mohammad Kamran Ikram, Narayanaswamy Venketasubramanian and Christopher Li-Hsian Chen

1365 Antidepressant switching patterns in the elderly Svetla Gadzhanova, Elizabeth E. Roughead and Lisa G. Pont

1375 Association of joint replacement surgery with incident dementia diagnosis in German claims data Stefan J. Teipel, Thomas Fritze, Martin Ellenrieder, Britta Haenisch, Wolfram Mittelmeier and Gabriele Doblhammer

$1385 \gamma$-Aminobutyric acid type A receptor binding affinity in the right inferior frontal gyrus at resting state predicts the performance of healthy elderly people in the visual sustained attention test Masato Kasagi, Tomokazu Motegi, Kosuke Narita, Kazuyuki Fujihara, Yusuke Suzuki, Minami Tagawa, Koichi Ujita, Hirotaka Shimada and Masato Fukuda

1393 What is the prevalence of untreated depression and death ideation in older people? Data from the Irish Longitudinal Study on Aging Robert Briggs, Katy Tobin, Rose Anne Kenny and Sean P. Kennelly

1403 The elder abuse and neglect phenomenon in the ultra-Orthodox Jewish society: social workers' perspectives Tova Band-Winterstein

Letter to the Editor 1413 Exploring dementia management attitudes in primary care: a key informant survey to primary care physicians in 25 European countries Hakan Yaman

1415 Response to "Parkinson's disease mild cognitive impairment classifications and neurobehavioral symptoms" Kyla-Louise Horne, Daniel J. Myall, Michael R. MacAskill, Tim J. Anderson and John C. Dalrymple-Alford

1417 Parkinson's disease mild cognitive impairment classifications and neurobehavioral symptoms clarification letter Richard Camicioli and Kirstie McDermott 